\title{
REVIEW
}

\section{Human gut-associated lymphoid tissues (GALT); diversity, structure, and function}

\author{
Urs M. Mörbe $\mathbb{D}^{1}$, Peter B. Jørgensen ${ }^{1}$, Thomas M. Fenton ${ }^{1}$, Nicole von Burg ${ }^{1}$, Lene B. Riis ${ }^{2}$, Jo Spencer ${ }^{3}$ and William W. Agace ${ }^{1,4}$
}

Gut-associated lymphoid tissues (GALT) are the key antigen sampling and adaptive immune inductive sites within the intestinal wall. Human GALT includes the multi-follicular Peyer's patches of the ileum, the vermiform appendix, and the numerous isolated lymphoid follicles (ILF) which are distributed along the length of the intestine. Our current understanding of GALT diversity and function derives primarily from studies in mice, and the relevance of many of these findings to human GALT remains unclear. Here we review our current understanding of human GALT diversity, structure, and composition as well as their potential for regulating intestinal immune responses during homeostasis and inflammatory bowel disease (IBD). Finally, we outline some key remaining questions regarding human GALT, the answers to which will advance our understanding of intestinal immune responses and provide potential opportunities to improve the treatment of intestinal diseases.

Mucosal Immunology (2021) 14:793-802; https://doi.org/10.1038/s41385-021-00389-4

\section{INTRODUCTION}

The human gut contains a diverse microbiota comprising approximately 40 trillion microorganisms ${ }^{1}$ which provide essential benefits for human health, including prevention of colonization by pathogens ${ }^{2}$, detoxification of bile acids ${ }^{3}$, metabolism of nondigestible carbohydrates ${ }^{4,5}$ and generation of key metabolites important for human health ${ }^{6}$. The intestinal immune system must respond appropriately to these beneficial microbes while providing active immunity against invading pathogens. Breakdown of this balance can lead to intestinal pathologies, including inflammatory bowel diseases (IBD; Crohn's disease (CD), and ulcerative colitis (UC)). Given these challenges, it is perhaps not surprising that the intestine contains the greatest number and diversity of immune compartments and immune cells in the body. Intestinal immune compartments can be broadly classified into inductive sites: the intestine-draining mesenteric lymph nodes (MLN) and the gut-associated lymphoid tissues $(\mathrm{GALT})^{7,8}$, in which adaptive immune cells undergo initial priming and differentiation, and effector sites: the intestinal lamina propria (LP) and epithelium in which primed adaptive immune cells localize and are maintained to promote barrier integrity and protective immunity.

The GALT of humans and mice includes both multi-follicular lymphoid tissues, such as Peyer's patches (PP) of the small intestine, and the far more numerous isolated lymphoid follicles (ILF) which are distributed along the length of the small and large intestines ${ }^{7}$. Additional types of GALT are specific to certain mammalian species, including the appendix in rabbits ${ }^{9}$ and humans ${ }^{10}$, the caecal and colonic patches in mice ${ }^{11,12}$, and rectal lymphoid tissues in humans ${ }^{13,14}$ and mice ${ }^{15}$. Most of our current understanding of the development, structure, and function of GALT comes from studies in mice (reviewed $\mathrm{in}^{16}$ ), and to what extent these observations are relevant to human GALT remains unclear. Limited understanding of human GALT is in part due to the inherent difficulty in obtaining human intestinal tissue, but also due to a lack of protocols allowing the isolation and analysis of human GALT. The current review focuses on human GALT, highlighting recent advances and discussing potential GALT functions in intestinal immune homeostasis and IBD. We compare findings to mouse GALT and highlight open questions regarding the importance of these enigmatic structures in human health and disease.

\section{MULTI-FOLLICULAR GALT OF THE HUMAN INTESTINE}

Some large, multi-follicular GALT are visible to the naked eye without specific staining methods or magnification. The most prominent of these structures are the PP of the small intestine, first described by Konrad Peyer in 1677 as "distinct aggregated nodules ${ }^{\prime 17}$, together with the lymphoid follicles of the vermiform appendix, which were described during the 19th and early 20th century $^{18,19}$. The following section will highlight our current understanding of the anatomy, location, and immune functions of these multi-follicular structures.

\section{Peyer's patches}

Human PP contain tens to hundreds of individual follicles and are found on the anti-mesenteric wall (Fig. 1a), along the entire length of the small intestine. Their density increases towards the terminal ileum, where they form a lymphoid ring at the ileocecal junction ${ }^{7,20-22}$. Similar to murine PP development, which is initiated around day 16.5 of embryogenesis by local clustering of group 3 innate lymphoid cells (ILC3) ${ }^{23}$, human PP development begins

\footnotetext{
${ }^{1}$ Mucosal Immunology group, Department of Health Technology, Technical University of Denmark, Kemitorvet, Lyngby, Denmark; ${ }^{2}$ Department of Pathology, Herlev Hospital, University of Copenhagen, Herlev, Denmark; ${ }^{3}$ Peter Gorer Department of Immunobiology, King's College London School of Medicine at Guy's King's College and St. Thomas' Hospitals, London, UK and ${ }^{4}$ Immunology Section, Lund University, BMC D14, Lund, Sweden

Correspondence: Urs M. Mörbe (mimurs@dtu.dk) or William W. Agace (wiag@dtu.dk)

These authors contributed equally: Urs M. Mörbe, Peter B. Jørgensen, Thomas M. Fenton
}

Received: 19 November 2020 Revised: 5 February 2021 Accepted: 6 February 2021

Published online: 22 March 2021 
a
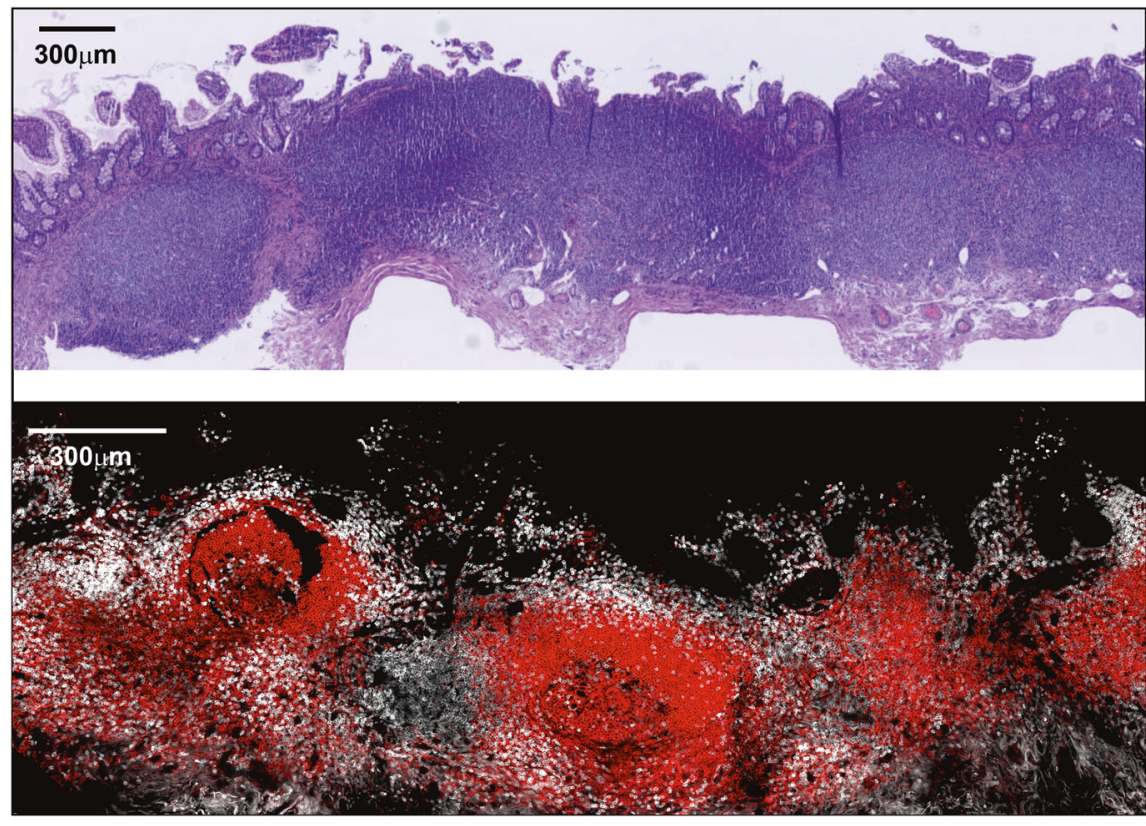

c

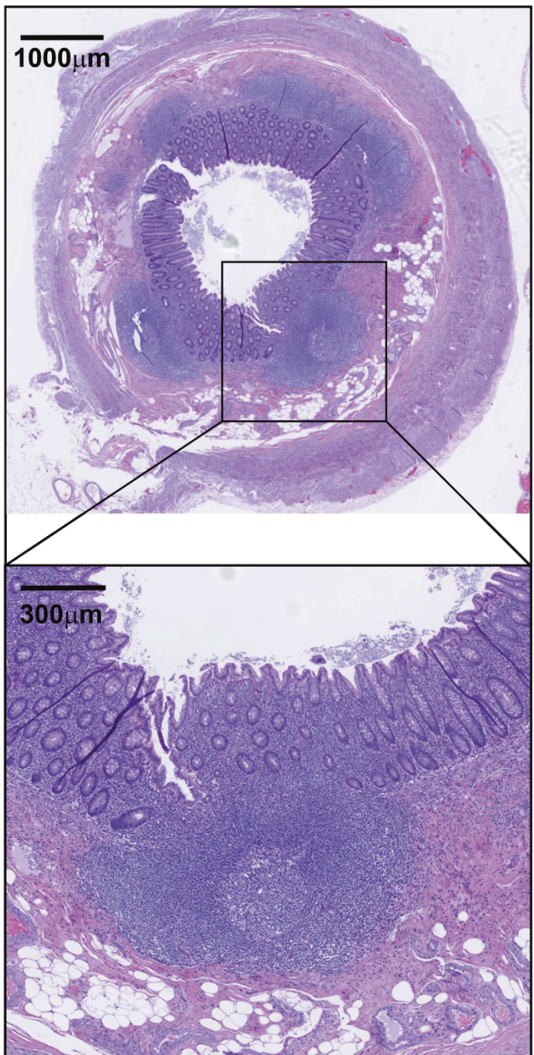

d

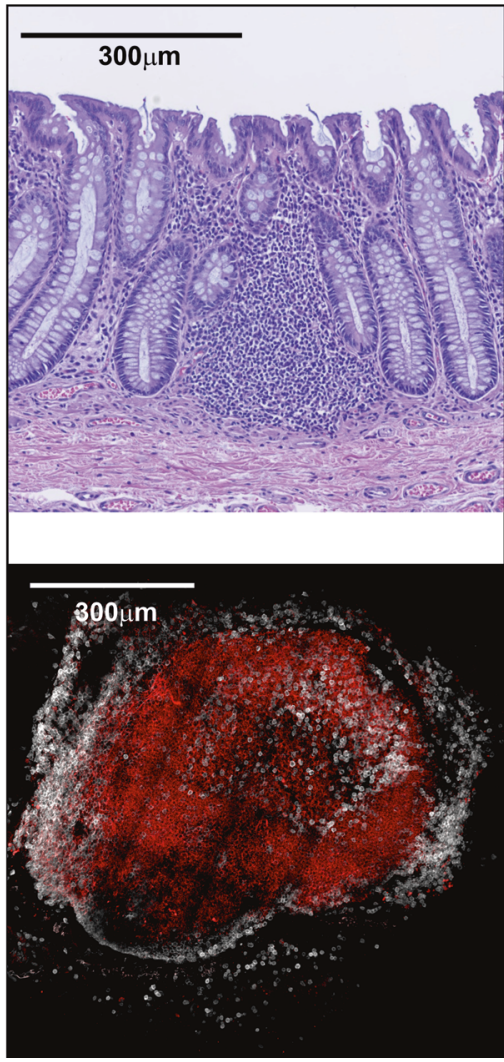

b

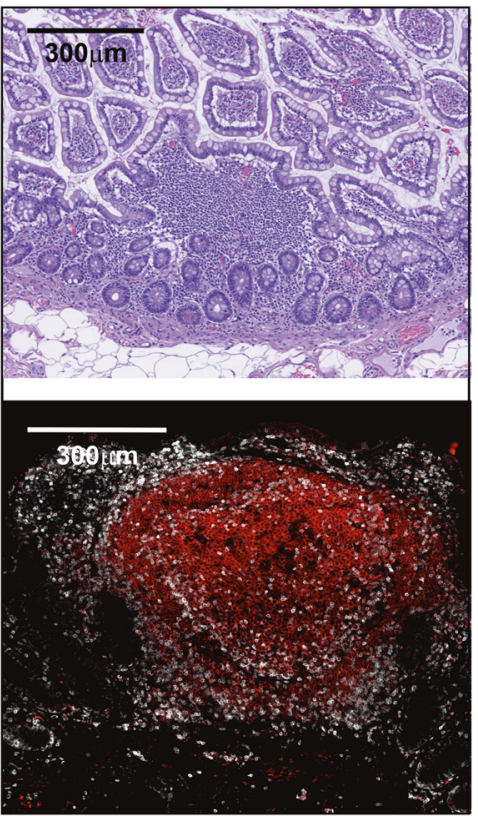

e

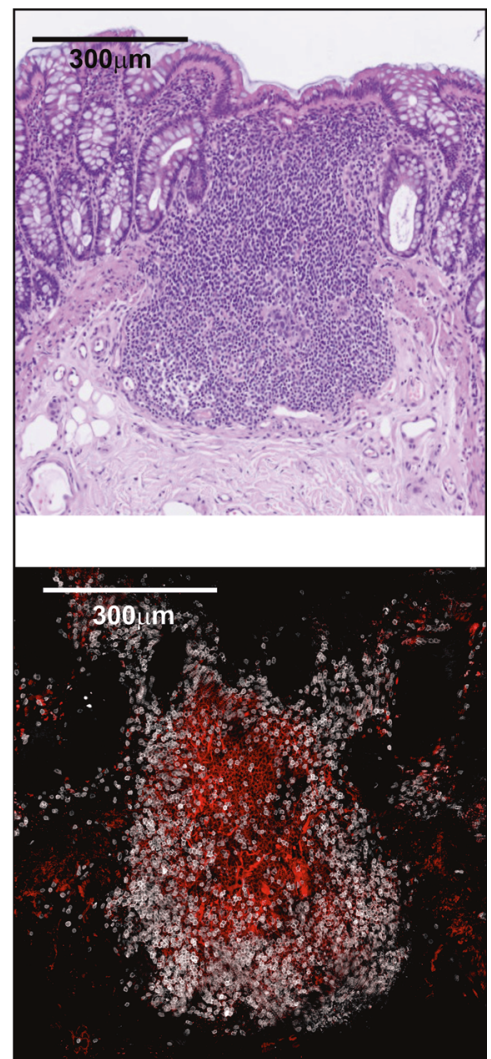

Fig. 1 The structure, size and organization of human GALT. H\&E and immunohistochemical stainings of a human (a) Peyer's patch, (b) ileal mucosal ILF (M-ILF), (c) vermiform appendix, (d) sigmoid colon M-ILF and (e) sigmoid colon submucosal ILF (SM-ILF). The immunohistochemistry images depict $\mathrm{CD}^{+} \mathrm{T}$ cells (white) and CD19 ${ }^{+} \mathrm{B}$ cells (red), showing the general organization of GALT with a central B cell cluster and a surrounding marginal T cell zone. PP and appendiceal GALT typically exist as a chain of lymphoid follicles located in the mucosa and submucosa of the intestine. M-ILF and SM-ILF both consist of a solitary follicle, which for M-ILF is entirely located in the mucosa and for SM-ILF is mostly located in the submucosa possessing only a small interface with the intestinal lumen. 
prenatally from around 14-16 weeks of gestation (reviewed in ${ }^{24}$ ). PP number and size continue to increase during childhood, peaking during early adolescence at around 240 PP, and then declining with age $^{20}$. While the immune cell composition and function ${ }^{25-27}$, as well as the size $e^{20,28}$ of PP may change during aging, the full extent of these changes remains to be investigated (Box 1).

PP are dedicated adaptive immune priming sites and contain several specialized microanatomical niches for the efficient initiation and propagation of immune responses (Fig. 2, reviewed in ref. ${ }^{29}$ ). Overlying the luminal surface of PP is a specialized follicle-associated epithelium (FAE), which is sparsely covered by mucus but rich in specialized epithelial cells known as microfold (M) cells ${ }^{30}$. In mice, $M$ cells have been shown to play a key role in shuttling luminal particulate antigens, including those from bacteria, viruses and SIgA-bound antigen into the PP parenchyma via transcytosis ${ }^{31-35}$, and this process is required for optimal $\lg \mathrm{A}$ responses to luminal antigen ${ }^{36}$. Whether $M$ cells in the FAE of human PP perform similar functions remains to be demonstrated directly, but experiments with in vitro differentiated human $M$ cells support this idea ${ }^{37}$. Human FAE also contains intraepithelial lymphocytes, although their function remains unclear ${ }^{38,39}$. On their basolateral side, $M$ cells form pockets which allow direct interaction with the immune cells found in the underlying subepithelial dome $(S E D)^{40}$. In humans, these pockets are primarily inhabited by $\mathrm{B}$ and $\mathrm{T}$ cells, the former mostly expressing IgM (a third of which also express $\operatorname{lgD}$ ), and the latter being primarily memory $\mathrm{CD}^{+}{ }^{+} \mathrm{T}_{\text {cells }}{ }^{40}$. The SED is dominated by professional antigen-presenting dendritic cells (DC) ${ }^{41-43}$ and other myeloid cells $s^{39,44}$, some of which have been observed to penetrate the basement membrane of the $\mathrm{FAE}^{43}$ and which, in mice, extend dendrites through $\mathrm{M}$-cell specific transcellular pores to sample luminal antigen ${ }^{45}$. The SED of human PP also contains diverse populations of memory $\mathrm{CD}^{+}{ }^{+} \mathrm{T}$ cells, and $\mathrm{B}$ cells of $\lg \mathrm{A}$, $\operatorname{lgM}$, and IgG isotypes ${ }^{38,44,46}$. The latter include activated FCRL4 ${ }^{+}$B cells $^{47}$, which secrete antibody in response to cytokines ${ }^{48}$ and TLRstimulation $^{49}$, rather than in response to BCR ligation ${ }^{48,49}$. Studies in mice have suggested that the SED may serve as a region of $\mathrm{CD}^{+} \mathrm{T}$ cell priming ${ }^{50,51}$ and DC-dependent IgA class-switching ${ }^{52}$. Activated $B$ cells in the SED of mice have been shown to acquire antigen from $M$ cells via their $B C R$ and shuttle it to the germinal center $(\mathrm{GC})^{53}$, potentially promoting the induction of $\lg A$ responses. Whether such processes occur in the SED of human PP remains unclear.

Histological studies of human PP have shown that B cell follicles containing active germinal centers (GC) sit in close proximity to the SED ${ }^{44,54-57}$. Surrounding the GC is a mantle zone of naive $\operatorname{lgD}^{+}$ $B$ cells, which is in turn surrounded by a larger marginal zone containing memory $B$ cells, predominantly of the $\lg A$ and $\lg M$ isotypes ${ }^{4,58,59}$. The marginal zone also contains $\operatorname{lgM}^{\text {hi }} \operatorname{lgD}^{+} B$ cells $^{44}$, which are phenotypically similar to the splenic marginal zone $B$ cells that generate innate-like responses to T-independent antigens ${ }^{60,61}$.

Along with B cell-rich follicles, human PP contain perifollicular T cell zones which serve as reservoirs for naïve and memory $T$ cells (Table 1$)^{25,62,63}$. Memory $\mathrm{CD}^{+} \mathrm{T}$ cells within the human PP are enriched in central memory $\mathrm{CD}^{+}{ }^{+} \mathrm{T}$ cells $(\mathrm{Tcm}), \mathrm{FOXP3}^{+} \mathrm{T}$ regulator cells $\left(T_{\text {reg }}\right)$ and $T$ follicular helper cells $\left(T_{f h}\right)$, and contain fewer polyfunctional cytokine-producing cells compared with the surrounding mucosa $^{25,62}$. In mice, lymphocytes enter PP from the circulation across high endothelial venules (HEV), in a process which requires expression of MAdCAM- 1 by HEV and its ligand a4 $\beta 7$ on circulating lymphocytes ${ }^{64-66}$. HEV in human PP also express MAdCAM-1 ${ }^{63}$, which binds $a 4 \beta 7$ on human lymphocytes ${ }^{67}$, suggesting that similar processes may govern the entry of circulating lymphocytes into human PP. Consistent with this notion, vedolizumab (anti-a4ß37) treatment of patients with mild IBD and concomitant HIV-1 infection was recently shown to reduce the size of GALT ${ }^{68}$. Finally, while human PP lack afferent lymphatics, diffuse efferent lymphatics are present on the submucosal side of PP and may act as exit points for immune cells ${ }^{63,69}$.

In mice, PP GCs are considered key sites for the generation of intestinal antibody responses by providing specialized niches for $B$ cells to undergo class switch recombination (CSR) and somatic hypermutation $(\mathrm{SHM})^{70,71}$. The findings that intestinal CSR is restricted to $\mathrm{PP}^{70}$, requires functional $T$ cells ${ }^{72}$ and CD40 signaling ${ }^{70,71}$, and that intestinal $\lg \mathrm{A}^{+}$plasma cells possess heavily mutated IgA heavy chains, indicative of $\mathrm{SHM}^{73}$, suggest that plasma cells in murine PP are predominantly generated via GC- and T cell-dependent mechanisms. Nevertheless, CD40 ${ }^{-/-}$ mice, that lack PP GC and have reduced levels of $\mathrm{CSR}^{70}$, are still able to generate normal levels of intestinal $\lg \mathrm{A}^{71}$. Thus, under certain conditions PP may support T cell-independent IgA plasma cell generation. Similar to their murine counterparts, human PP are also considered key sites for the induction of intestinal antibody responses ${ }^{59,74}$, a notion mainly derived from comparative analyses showing that human and murine PP have a similar organization and cellular composition ${ }^{44,75,76}$. Further indication that human PP contribute to the intestinal plasma cell pool comes from findings that IgA clones present within human ileal PP are overrepresented in the LP of the ileum, compared with the LP of the colon ${ }^{62}$. This also suggests that, as in mice ${ }^{11,77-79}$, human PP may preferentially drive immune responses restricted to the small intestine. Consistent with this, we found that $\lg \mathrm{A}^{+}$plasmablasts of the small intestinal LP, but not of the colonic LP, express the small intestinal homing receptor CCR9 ${ }^{62}$, which in mice is induced selectively on adaptive immune cells during their priming in PP and in small intestinal $M L N^{80-82}$. These findings underscore the important role of PP as immune priming sites of the small intestine, and as a key source of small intestinal $L P \lg A^{+}$ plasma cells.

PP are also associated with human B cell maturation, for example by supporting the clonal expansion and somatic diversification of the systemic marginal zone $B$ cell subset ${ }^{59}$. Additionally, it has been suggested that traffic through PP contributes to the maturation of immature transitional $B$ cells and may play a role in the deletion of autoreactive $B$ cell clones ${ }^{64}$.

\section{Vermiform appendix}

The human vermiform appendix has long been considered a vestigial organ and appendectomy is not associated with any long-term negative effects ${ }^{83}$. Nevertheless, the appendix has been proposed to act as a "sanctuary" for intestinal bacteria by offering protection from diarrheal clearing and intestinal peristalsis ${ }^{10,84}$. It may also function as an immune cell priming site similar to other $\mathrm{GALT}^{10,59,85,86}$. Interestingly, as discussed further below, appendectomy is protective against ulcerative colitis ${ }^{87-90}$, suggesting that this organ may retain some physiological functions.

Similar to PP development, appendiceal GALT development begins around gestational week 15-16 $6^{91,92}$, although the appendix itself already starts developing around gestational week $8^{93}$. While the processes driving the development and maturation of lymphoid structures in the appendix are not well understood, these structures mature in the years after birth into a chain of T cell- and B cell-rich lymphoid follicles embedded in the submucosa and LP (Fig. 1c) $^{10,25,59,91,94}$. Like their counterparts in PP, appendiceal GALT follicles possess a dome structure facing towards the intestinal lumen, overlaid with an FAE containing $M$ cells ${ }^{95}$. Distinct perifollicular $T$ cell zones and central $B$ cell follicles can be found ${ }^{59}$, as well as monocytes and activated $\mathrm{CD}^{+} 6^{+} \mathrm{DC}^{25,59,96}$ (Table 1). The appendiceal GALT is enriched in naïve and $T_{c m}$ cells $s^{25}$ and possesses $\mathrm{GC}^{10,59}$, together with $\mathrm{B}$ cells at different stages of development and activation, implying that the vermiform appendix plays a role as an adaptive immune inductive site. As in PP, appendiceal GC contain a central cluster of GC B cells surrounded by a thin mantle zone containing naïve $B$ cells, as well as a marginal zone containing marginal zone $B$ cells and naïve $B$ cells ${ }^{59,97}$. Memory $B$ cells are 


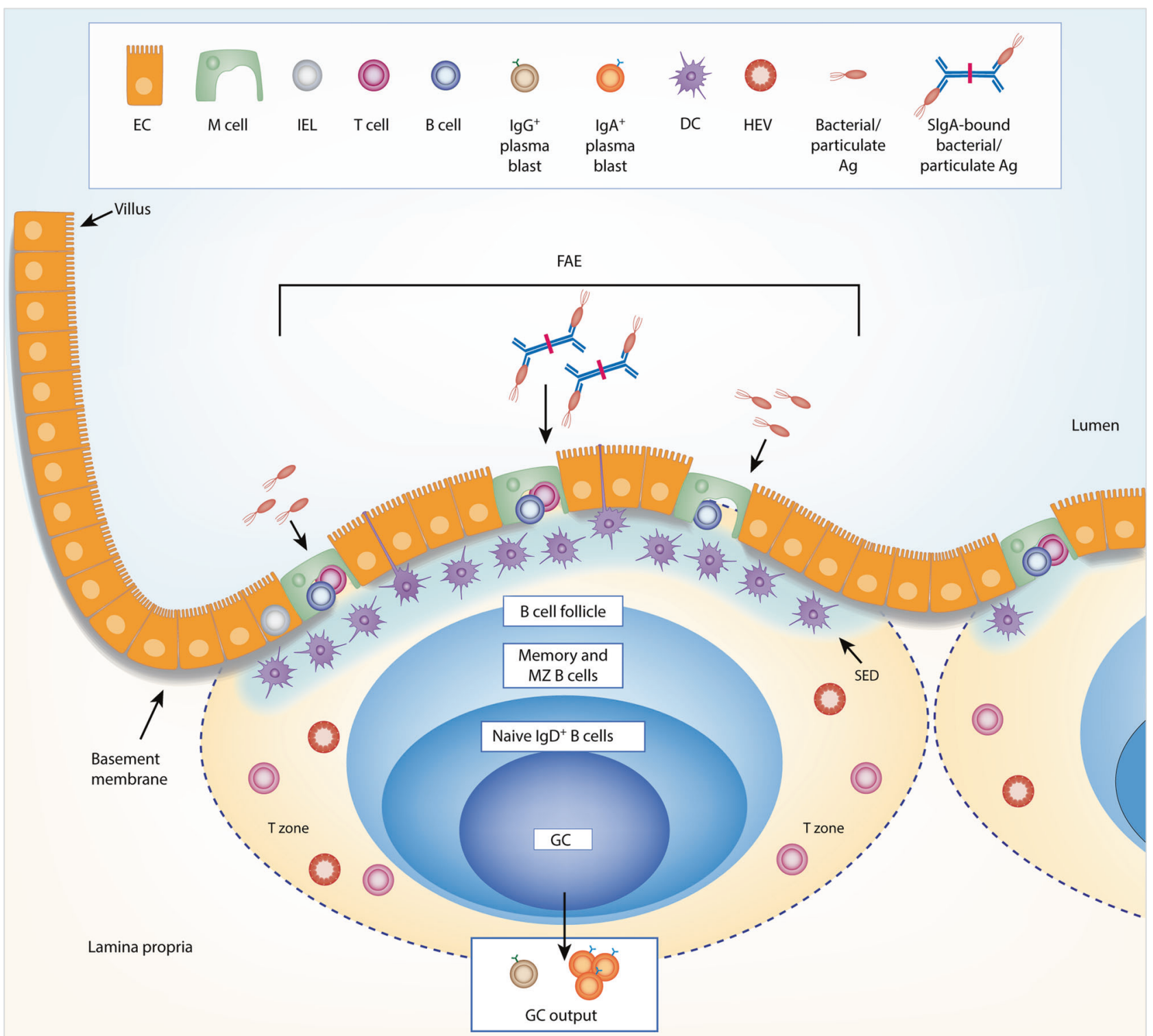

Fig. 2 Cellular composition of a human PP follicle as example of human GALT. PP follicles are in intimate association with the intestinal lumen and possess a specialized FAE containing $M$ cells that shuttle free and IgA-bound antigen into the PP. Below the FAE, PP possess a SED region rich in antigen-presenting cells. Tightly associated with the SED is the underlying $B$ cell follicle consisting of an outer marginal zone harboring memory and marginal zone B cells, a thin mantle zone accommodating naïve B cells, and a central GC, contributing to the generation of $\lg \mathrm{A}^{+}$plasmablasts that seed the surrounding small intestine. B cell follicles of PP are separated by perifollicular $\mathrm{T}$ cell zones (dotted lines). FAE follicle-associated epithelium, SED subepithelial dome, GC germinal center, Ag antigen.

located in the SED and periphery of the follicle in proximity to the $\mathrm{FAE}^{46,59}$. Class-switched $\operatorname{lgA} \mathrm{A}^{+}$cells can be detected in appendiceal GALT, but they also contain memory $\operatorname{lgM}^{+} B$ cells ${ }^{86}$ and more $\operatorname{lgG}^{+} B$ cells than the surrounding $\mathrm{LP}^{46,98}$. Thus, the appendix may serve as a local environment for class-switching and as a reservoir of classswitched memory B cells.

Together, these findings suggest that the human vermiform appendix represents a bona fide adaptive immune inductive site with a similar structure and immune cell composition to PP. It remains unclear whether immune responses initiated within this site differ from those in the PP, and whether the human appendix supports site-specific regional immunity within the intestine, as recently suggested for human $\mathrm{PP}^{62}$.

Other multi-follicular GALT

GALT consisting of more than one lymphoid follicle are relatively rare in the human large intestine during homeostasis, although a few poorly characterized multi-follicular structures have been described in the cecum and proximal colon ${ }^{62}$, together with rare multi-follicular structures around the anal canal, sometimes referred to as the rectal tonsil ${ }^{13,14}$. The exact structure, function, development, cellular composition, and prevalence of these multifollicular GALT remains unclear.

\section{ISOLATED LYMPHOID FOLLICLES}

Consisting of a single lymphoid follicle with a diameter between 0.1 and $1.3 \mathrm{~mm}^{62,99}$, ILF are substantially smaller than PP or the follicle chain of the vermiform appendix. However, as there are an estimated 30,000 ILF in the human intestine ${ }^{100-103}$, they collectively constitute a major GALT compartment in humans. ILF are found along the length of the intestine, although their cellular composition, density and location within the gut wall varies between intestinal segments. Using novel techniques to 


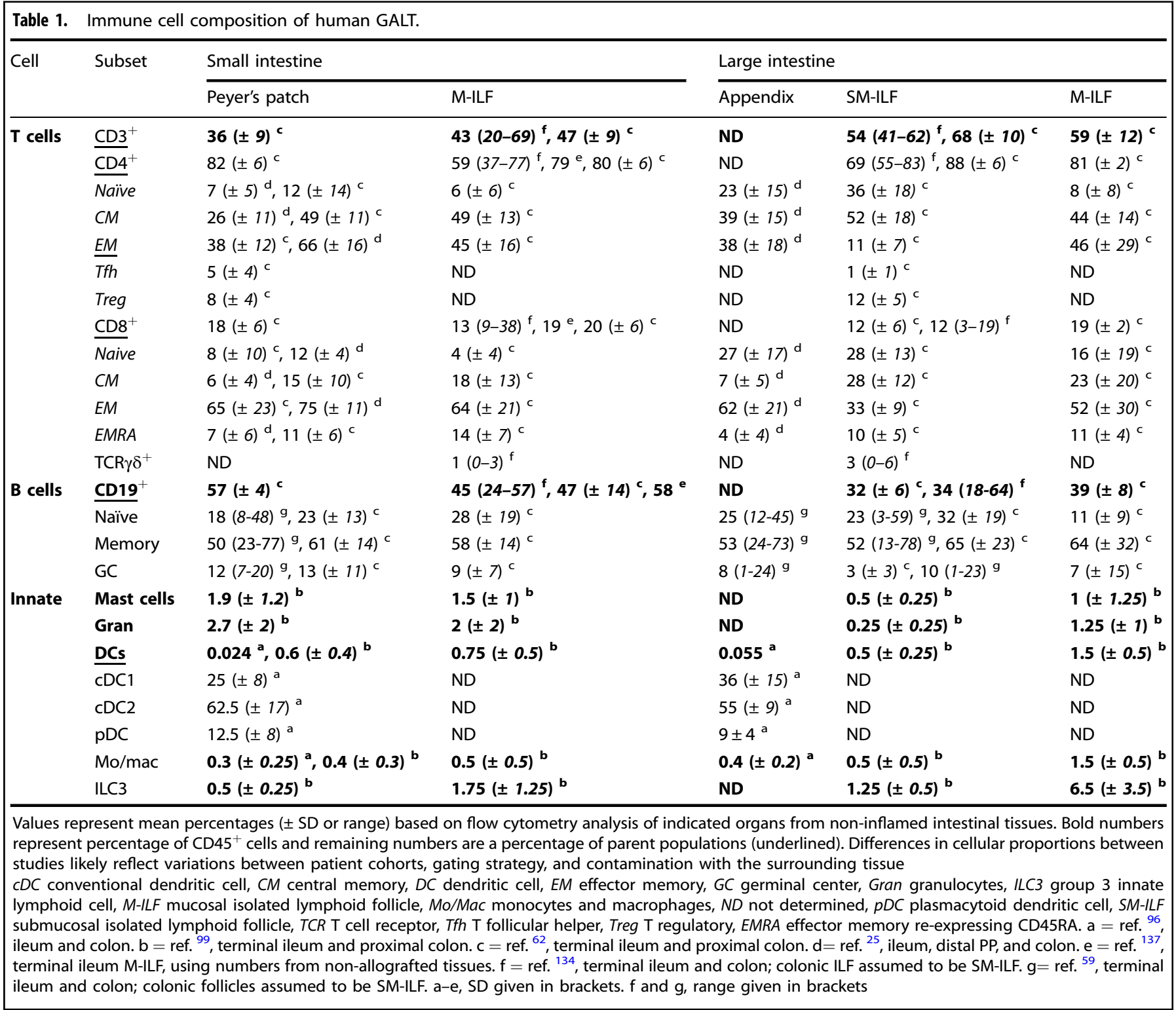

identify and quantify ILF in the human intestine, we recently described the presence of distinct kinds of ILF, one of which resides solely within the mucosal LP (hereafter termed mucosal ILF, M-ILF), while the other protrudes into the overlying LP but resides mainly in the submucosa (hereafter termed SM-ILF) ${ }^{62,99}$ (Fig. 1b, d, and e). The distribution of M-ILF and SM-ILF differs along the length of the intestine, with M-ILF largely restricted to the ileum and distal colon, while SM-ILF are distributed along the colon and are only rarely found in the ileum ${ }^{62}$.

\section{ILF Development}

While ILF have been identified in a wide range of mammalian species $^{104-107}$, our current understanding of their development derives primarily from studies in mice. Murine ILF development begins 1-3 weeks after birth with the formation of cryptopatches $(C P)^{108}$, which are pericryptal lymphoid aggregates whose development requires $\mathrm{RORYt}^{+} \mathrm{C}^{-\mathrm{kit}^{+}} \mathrm{ILC}$, and which also contain $\mathrm{CD}_{11 \mathrm{c}^{+}} \mathrm{DC}$ and $\mathrm{VCAM}^{+}{ }^{\mathrm{PDPN}^{+}}$mesenchymal stromal cells ${ }^{12,72,109,110}$. CP maturation into ILF depends on the sensing of intestinal $\mathrm{AhR}^{111}$ and microbiota-derived ligands ${ }^{112,113}$. The transition to mature ILF is associated with the formation of a central B cell cluster making up to $50-70 \%$ of total cells ${ }^{108,114,115}$, surrounded by a ring of ILC3 that constitute approximately $25 \%$ of total cells ${ }^{114}$.

Whether CP-like structures exist in the human intestine remains unclear. This likely reflects difficulties in obtaining pediatric intestinal tissues for analysis ${ }^{116}$, although it has also been suggested that humans may completely lack CP ${ }^{104,117}$. Structures described as "lymphocyte-filled villi" have been proposed as possible developmental precursors of mature human ILF ${ }^{117}$ and, more recently, clusters of $\mathrm{CKit}^{+} \mathrm{CCR}^{+}$putative ILC3 were identified in the human colon and were suggested to be $C P$, although their cellular content and organization were not assessed in detail ${ }^{18}$. Of note, ILC3 are enriched in human M-ILF and SM-ILF compared with LP ${ }^{99}$, suggesting that ILC3 may be involved in the development, maintenance and/or function of human ILF, as they are in mice ${ }^{111,119,120}$. The time window of ILF development differs substantially between species however: in the human intestine, lymphocyte accumulations reminiscent of ILF can be observed before and around birth ${ }^{121-123}$, in line with a recent finding that stromal cells with a phenotype reminiscent of GALT stromal cells are also already detectable in the human fetal colon $^{124}$. This suggests that a host microbiome is not required for the development of at least some human ILF. 
The signals driving ILF development in the small intestine and colon in mice are partially distinct, with microbiota driving ILF maturation in the small intestine, but inhibiting this process in the colon $^{12,113}$. Murine small intestinal ILF also uniquely depend on RANKL $^{125}$ and $\mathrm{CXCL}^{13}{ }^{12}$, while colonic ILF development is uniquely promoted by IL-23 and suppressed by IL-25 $5^{113}$. Although the role of these factors in human ILF development is unknown, these findings suggest that ILF development is distinct in different parts of the intestine, perhaps reflecting variation in the local microenvironment such as abundance of food or microbiotaderived metabolites including short chain fatty acids ${ }^{126}$ and retinoic acid $^{127}$, as well as microbial load and diversity ${ }^{7,128,129}$. These factors together may contribute also to the distinct development and distribution of human M-ILF and SM-ILF along the length of the intestine.

After birth, ILF can be found at all ages in humans ${ }^{25,101}$, with their total numbers peaking in the first few years of life $^{25,102}$, indicating a process of postnatal maturation. Importantly, none of the above-mentioned human studies distinguished M-ILF from SM-ILF, and whether these different structures develop during similar or distinct developmental stages remains to be determined. Future studies applying the techniques for isolating anatomically distinct GALT ${ }^{99}$, in individuals of different ages, may help resolve these issues.

\section{Structure and composition of human ILF}

Human M-ILF and SM-ILF both contain an FAE with putative antigen-sampling $M$ cells ${ }^{62,130,131}$, although $M$ cell-dependent uptake of particulate luminal antigens has yet to be formally demonstrated in both mouse and human ILF. Underlying the FAE of both M-ILF and SM-ILF is an SED which is rich in CD11c ${ }^{+}$ antigen-presenting cells ${ }^{62}$, a central $B$ cell follicle which may contain a GC and is encircled by $T$ cells ${ }^{62,130}$, a vascular network that includes both MAdCAM-1 ${ }^{+}$and MAdCAM-1 $1^{-}$vessels ${ }^{40,44,62}$, and a surrounding lymphatic network ${ }^{62,117,130}$. Due to the lack of a clear boundary between ILF and the surrounding LP, there is a "mixed cell zone" at their interface, with decreasing cellular

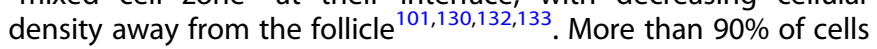
within M-ILF and SM-ILF are lymphocytes, with a slightly higher proportion of T cells compared with B cells ${ }^{62}$ (Table 1). This is in marked contrast to murine ILF, which consist mostly of B cells and only a few scattered T cells ${ }^{104,108,109}$, although it should be noted that $T$ cell numbers increase in murine ILF with ageing ${ }^{115}$. Most T cells in human ILF are $\mathrm{CD}^{+}$and, similar to PP, both $\mathrm{CD}^{+}$and $\mathrm{CD}^{+} \mathrm{T}$ cell populations in ILF contain more $\mathrm{T}_{\mathrm{cm}}$ and naïve $\mathrm{T}$ cells than in the LP 25,62 . As in PP, memory CD4 ${ }^{+} T$ cells in ILF contain fewer poly-functional cytokine-producing cells and larger proportions of FOXP3 ${ }^{+}$Tregs compared to surrounding $\mathrm{LP}^{25,62}$. Finally, both M-ILF and SM-ILF contain PD $-1^{+}$putative $T_{\text {fh }}$ cells ${ }^{25,62}$, consistent with the presence of GC. The B cell compartment of ILF is also distinct from that of the LP, as it lacks plasma cells and contains high proportions of naïve and memory $B$ cells, as well as small numbers of GC and marginal zone-like $B$ cells ${ }^{59,62}$. Clonal analysis suggests that memory $B$ cells recirculate between different $\mathrm{GALT}^{59}$ and consistent with this, the proportions of $\operatorname{lgM}^{+}, \lg \mathrm{G}^{+,}$and $\lg \mathrm{A}^{+}$cells within the memory B cell compartment of ILF are similar between ILF from the same patient ${ }^{62}$.

Despite these similarities, the structure and cellular composition of M-ILF and SM-ILF differ in several aspects ${ }^{62,117,130}$. Anatomically, SM-ILF are located in mucosal invaginations with most of their mass in the intestinal submucosa, with only a small area in the mucosa accessible to the intestinal lumen ${ }^{56,62,99,130}$. On the other hand, M-ILF are fully located in the mucosa and present a large domed FAE surface to the lumen ${ }^{56,62,99}$. M-ILF are also on average smaller $^{132}$, but with a larger SED ${ }^{130}$, contain more FAE intraepithelial lymphocytes ${ }^{132}$, have a higher B:T cell ratio ${ }^{132,134}$, higher frequencies of GC B cells ${ }^{62}$, and are enriched in ILC3 compared with SM-ILF ${ }^{99}$. M cells present in the FAE of M-ILF but not SM-ILF express the mature $M$ cell marker GP- $2^{62}$, which in mice has been shown to promote the uptake of type-1 fimbriated bacteria ${ }^{135}$, indicating potential differences in $\mathrm{M}$ cell function between these sites. Additionally, SM-ILF contain a greater proportion of naïve T cells compared with both M-ILF and PP, even when comparing SM-ILF and M-ILF from the same intestinal segment ${ }^{62}$. Whether such differences in cellular composition reflect differences in the type or amount of luminal antigens sampled by these structures remains to be determined (Box 1).

Function of human ILF in immune homeostasis Murine ILF are thought to be an important source of T-cellindependent $\lg \mathrm{A}$ responses ${ }^{72}$, and a similar role has been proposed for human ILF on the basis that they contain dendritic cells and macrophages expressing A proliferation-inducing ligand (APRIL), as well as B cells expressing Transmembrane activator and CAML interactor $(\mathrm{TACl})^{41,121}$. However, human intestinal $\lg \mathrm{A}^{+}$ clones show evidence of extensive somatic hypermutation ${ }^{73,136}$, indicating that T-cell-independent IgA differentiation in humans is probably limited. Indeed the presence of Tfh cells ${ }^{62,137}$, $\mathrm{GC}^{56,117,122,137,138}$, follicular dendritic cells ${ }^{62}, \mathrm{CD} 40 \mathrm{~L}^{2}$ expression ${ }^{121}{ }^{\prime}$, and high levels of the enzyme required for somatic hypermutation in GC B cells, activation-induced deaminase (AID) ${ }^{41,86,121,138}$, suggest that human ILF act as key priming sites for T-celldependent $B$ cell responses. Consistent with this notion, recent analyses of GC B cell populations indicate that ILF may support the generation of $\lg A 1, \lg A 2, \lg G$, and $\lg M B$ cell responses ${ }^{59,62,86}$. Whether the acquisition of a particular isotype is influenced by an ILF's location within or along the length of the intestine, and the nature of the signals driving these different responses, remain to be determined (Box 1). Notably, we recently found that IgA clones present in colonic SM-ILF were overrepresented in the colonic LP compared with the ileal $L P^{62}$, indicating that colonic SM-ILF contribute to local $B$ cell responses in the colon, reflecting the role of PP in the small intestine. Furthermore, we found that $\lg \mathrm{A}^{+}$ plasma cells in the colon, but not in the small intestine, expressed GPR15 $5^{62}$, a receptor which in mice has been shown to mediate $T$ cell recruitment to the colon LP $P^{139,140}$. Whether GPR15 is induced on newly generated plasmablasts in colonic SM-ILF remains unclear.

Despite the above findings, many important questions remain about human ILF function in intestinal homeostasis (Box 1), including their contribution to the generation of effector and regulatory T cell responses, whether M-ILF and SM-ILF have similar or distinct immune functions, and the functional implications of the distinct distribution of M-ILF and SM-ILF along the intestine.

\section{GALT IN PROTECTION FROM MUCOSAL PATHOGENS}

While studies in mice have demonstrated a key role for GALT in the induction of local immune responses and protection against mucosal pathogens ${ }^{141-143}$, evidence that human GALT are involved in similar processes remains circumstantial. For example, $M$ cells in GALT appear to be the principal route of entry for several human pathogens such as Salmonella ${ }^{144}$, Yersinia ${ }^{145,146}$, and Shigella spp ${ }^{147}$, poliovirus ${ }^{148}$, mycobacteria ${ }^{149}$ and prions ${ }^{150^{\prime}}$, and oral vaccines against many of these pathogens are more effective than their parenteral equivalents ${ }^{151-155}$. Addressing the direct involvement of human GALT in such processes is likely to be complicated by the difficulty in obtaining appropriate GALT material from infected or vaccinated individuals (Box 1).

\section{GALT IN IBD PATHOGENESIS}

$C D$ and $U C$ are the two major subtypes of IBD, both involving chronic immune responses against the intestinal microbiota, and both associated with aberrant lymphocyte responses ${ }^{156-159}$. However, it is not known where and how these pathological 
Box 1: Some remaining key questions in GALT research While recent studies have substantially advanced our understanding of human GALT, many questions remain with potentially important implications for our understanding of intestinal immunity. These include:

- What signals drive the development and distribution of GALT structures along the intestine?

- What is the impact of ageing on GALT and the associated immune cell compartment?

- Do different types of GALT play distinct roles in intestinal immune responses?

- What antigens do distinct GALT sample and respond to, and does this change in IBD?

- What role do GALT play in the initiation and maintenance of IBD?

What role do GALT play in immunity to intestinal pathogens?

responses are initiated. In the following paragraphs we discuss the potential role of GALT in the onset and perpetuation of IBD.

GALT in Crohn's disease

While CD can affect all layers of the gut wall at any site from the mouth to the anus, CD inflammation occurs most frequently in the ileum and proximal colon ${ }^{160}$, and it is characterized by "skip lesions" in which areas of inflammation are interrupted by noninvolved areas ${ }^{160}$. The earliest signs of CD which can be detected by colonoscopy are inflammatory lesions in the FAE of ILF and PP, known as aphthous or aphthoid ulcers ${ }^{161-164}$. These can progress into the large transmural lesions responsible for the characteristic symptoms and high morbidity of $C D^{161,164}$, suggesting that GALT may act as key sites of disease initiation in CD.

Recent single-cell RNA-sequencing studies have demonstrated that the affected intestine of CD patients is enriched in cell types associated with organized lymphoid structures, including $\mathrm{HEV}^{158,165,166}$, naïve and memory $B$ cells, $T_{\text {reg, }}$ and naïve or central memory $T$ cells $^{158}$. Whether this is due to enlarged GALT or de novo generation of tertiary lymphoid organs (TLO) in the intestine of CD patients remains unclear, since there are currently no definite criteria to distinguish ILF from TLO (Box 2). Nevertheless, increased numbers of lymphocytes have been reported in the ILF of CD patients ${ }^{133}$ and we have recently shown that presumptive SM-ILF are markedly enlarged in the inflamed large intestine of $C D$ patients ${ }^{99}$, indicating that ILF are sites of adaptive immune activation in CD. Whether these processes play a pathogenic role or help counteract inflammation in established CD remains an open question (Box 1). In support of the former, mutations in NOD2, which is a major genetic risk factor for $C D$, have recently been associated with increased retrograde transport of bacteria-lgA complexes from the lumen into PP, potentially through a direct effect on $M$ cells ${ }^{167}$, and perhaps promoting the inflammation of CD.

GALT in ulcerative colitis

UC usually starts in the rectum and spreads along the large intestine, but rarely progresses beyond the ileocecal junction into the small intestine ${ }^{160,168}$. In contrast to $C D$, skip lesions are not seen in UC, while the inflammation is normally restricted to the mucosal layer and does not involve GALT-associated aphthoid ulcers $^{160,163}$. However, structures called "basal lymphoid aggregates" have been described in the inflamed mucosa of UC patients ${ }^{169-173}$. Consistent with this, the inflamed colon of UC patients is enriched in cells and molecules associated with organized lymphoid structures, including $\mathrm{HEV}^{166}$, TNF-producing $\mathrm{T}_{\text {reg }}{ }^{156,159,165}, \mathrm{~T}_{\mathrm{CM}}{ }^{165}$, follicular $\mathrm{B}$ cells ${ }^{159}$, the $\mathrm{T}$ cell-recruiting chemokine 'CCL19 $19^{174}$, and lymphoid tissue-associated stromal cells $^{159,174}$. Additionally, the numbers and size of visible GALT have been shown to increase in UC-affected tissues ${ }^{130,133,175}$. However, it remains unclear whether these basal lymphoid aggregates represent enlarged ILF or inflammation-induced TLO (Box 2). UC is
Box 2: The structure and functions of TLO

TLO are lymphocyte accumulations within peripheral tissues that develop de novo in response to local inflammation ${ }^{177}$ and they can be found in all layers of the gut wall during IBD ${ }^{177,178}$. As TLO include structures with varying degrees of organization, sometimes including clearly-delineated $T$ and $B$ cell zones ${ }^{177}$, it may be challenging to distinguish between ILF and intestinal TLO. Resolving the potential structural and functional differences between ILF and TLO, and whether they play similar or distinct immunological roles in IBD might reveal novel disease-driving mechanisms but will require careful analysis of their structure and cellular composition in the early diseased intestine.

also often preceded by appendiceal inflammation, and surgical removal of the vermiform appendix correlates with a lower risk of the development of UC, as well as less severe symptoms after disease onset ${ }^{87-90}$. While further studies are required to assess potential causality, a possible explanation for these findings is that appendiceal GALT contributes to the generation of pathogenic adaptive immune responses in UC.

Collectively, these studies suggest that human GALT could be involved in the initiation and perpetuation of inflammation in IBD, potentially through the generation of aberrant $\mathrm{T}$ cell ${ }^{156,158,159,169}$ and $B$ cell responses ${ }^{157,158,176}$. However, it remains possible that GALT activation in IBD is merely a consequence of sustained intestinal inflammation, rather than initiating and driving the inflammatory process (Box 1).

\section{CONCLUDING REMARKS AND REMAINING QUESTIONS}

The existence of GALT within the human intestine has been known for centuries ${ }^{17,101,102}$, and recent studies have substantially advanced our knowledge of their heterogeneity, abundance, composition, and function. Despite these findings, major knowledge gaps remain regarding their development and role in intestinal homeostasis, infection, and inflammatory disease (Box 1). Answering such questions will likely lead to an enhanced understanding of how immune responses are initiated and regulated within the human intestine, and with it the potential of identifying novel mucosal vaccination strategies and ways to treat chronic intestinal disease.

\section{ACKNOWLEDGEMENTS}

The authors thank Professor A. Mowat (Glasgow University) for valuable feedback during preparation of the manuscript. This work was supported by grants from the Lundbeck Foundation (R155-2014-4184), Denmark and the Gut Cell Atlas, an initiative funded by the Leona M. and Harry B. Helmsley Charitable Trust, US.

\section{AUTHOR CONTRIBUTIONS}

U.M., P.J., and T.F. and W.A. wrote the manuscript, which was revised and approved by all authors. N.B. designed the figures, J.S. discussed literature and gave input on the manuscript, L.R. acquired the histological images.

\section{ADDITIONAL INFORMATION}

Competing interests: The authors declare no competing interests.

Publisher's note Springer Nature remains neutral with regard to jurisdictional claims in published maps and institutional affiliations.

\section{REFERENCES}

1. Sender, R., Fuchs, S. \& Milo, R. Are we really vastly outnumbered? Revisiting the ratio of bacterial to host cells in humans. Cell 164, 337-340 (2016).

2. Pickard, J. M., Zeng, M. Y., Caruso, R. \& Núñez, G. Gut microbiota: role in pathogen colonization, immune responses, and inflammatory disease. Immunol. Rev. 279, 70-89 (2017).

3. Staley, C., Weingarden, A. R., Khoruts, A. \& Sadowsky, M. J. Interaction of gut microbiota with bile acid metabolism and its influence on disease states. Appl. Microbiol. Biotechnol. 101, 47-64 (2017). 
4. Gill, S. R. et al. Metagenomic analysis of the human distal gut microbiome. Science 312, 1355-1359 (2006).

5. Bäckhed, F., Ley, R. E., Sonnenburg, J. L., Peterson, D. A. \& Gordon, J. I. Hostbacterial mutualism in the human intestine. Science 307, 1915-1920 (2005).

6. Oliphant, K. \& Allen-Vercoe, E. Macronutrient metabolism by the human gut microbiome: major fermentation by-products and their impact on host health. Microbiome 7, 91 (2019).

7. Mowat, A. M. \& Agace, W. W. Regional specialization within the intestinal immune system. Nat. Rev. Immunol. 14, 667-685 (2014).

8. Brandtzaeg, P., Kiyono, H., Pabst, R. \& Russell, M. W. Terminology: nomenclature of mucosa-associated lymphoid tissue. Mucosal Immunol. 1, 31-37 (2008).

9. Beyaz, F., Ergün, E., Bayraktaroğlu, A. G. \& Ergün, L. The identification of intestinal $M$ cells in the sacculus rotundus and appendix of the Angora rabbit. Vet. Res. Commun. 34, 255-265 (2010).

10. Kooij, I. A. et al. The immunology of the vermiform appendix: a review of the literature. Clin. Exp. Immunol. 186, 1-9 (2016).

11. Masahata, K. et al. Generation of colonic lgA-secreting cells in the caecal patch. Nat. Commun. 5, 3704 (2014).

12. Baptista, A. P. et al. Colonic patch and colonic SILT development are independent and differentially regulated events. Mucosal Immunol. 6, 511-521 (2013).

13. Farris, A. B., Lauwers, G. Y., Ferry, J. A. \& Zukerberg, L. R. The rectal tonsil: a reactive lymphoid proliferation that may mimic lymphoma. Am. J. Surg. Pathol. 32, 1075-1079 (2008).

14. Hong, J. B. et al. Rectal tonsil: a case report and literature review. World J. Gastroenterol. 21, 2563-2567 (2015).

15. Cesta, M. F. Normal structure, function, and histology of mucosa-associated lymphoid tissue. Toxicol. Pathol. 34, 599-608 (2006).

16. Buettner, M. \& Lochner, M. Development and function of secondary and tertiary lymphoid organs in the small intestine and the colon. Front Immunol. 7, 342 (2016).

17. Peyer, J. K. Exercitatio anatomico-medica de glandulis intestinorum earumque usu et affectionibus Riedingius (1677).

18. Aschoff, L. Die Wurmfortsatz-Entzündung: eine pathologisch-histologische und pathogenetische Studie. Jena, Gustav Fischer (1908).

19. Ziegler R. O. Ueber die solitären und Peyerschen Follikel. Diss. inaug., Würzburg, Druck von F.E. Thein (1850).

20. Cornes, J. S. Number, size, and distribution of Peyer's patches in the human small intestine: II. The effect of age on Peyer's patches. Gut 6, 230-233 (1965).

21. Van Kruiningen, H. J., West, A. B., Freda, B. J. \& Holmes, K. A. Distribution of Peyer's patches in the distal ileum. Inflamm. Bowel Dis. 8, 180-185 (2002).

22. Jung, C., Hugot, J. P. \& Barreau, F. Peyer's patches: the immune sensors of the intestine. Int. J. Inflam. 2010, 823710 (2010).

23. Veiga-Fernandes, $\mathrm{H}$. et al. Tyrosine kinase receptor RET is a key regulator of Peyer's Patch organogenesis. Nature 446, 547-551 (2007).

24. Hoorweg, K. \& Cupedo, T. Development of human lymph nodes and Peyer's patches. Semin. Immunol. 20, 164-170 (2008).

25. Senda, T. et al. Microanatomical dissection of human intestinal T-cell immunity reveals site-specific changes in gut-associated lymphoid tissues over life. Mucosal Immunol. 12, 378-389 (2019).

26. Koga, T. et al. Evidence for early aging in the mucosal immune system. J. Immunol. 165, 5352-5359 (2000).

27. Kobayashi, A. et al. The functional maturation of $M$ cells is dramatically reduced in the Peyer's patches of aged mice. Mucosal Immunol. 6, 1027-1037 (2013).

28. Cornes, J. S. Number, size, and distribution of Peyer's patches in the human small intestine: I. The development of Peyer's patches. Gut 6, 225-229 (1965).

29. Junt, T., Scandella, E. \& Ludewig, B. Form follows function: lymphoid tissue microarchitecture in antimicrobial immune defence. Nat. Rev. Immunol. 8, 764-775 (2008).

30. Owen, R. L. \& Jones, A. L. Epithelial cell specialization within human Peyer's patches: an ultrastructural study of intestinal lymphoid follicles. Gastroenterology 66, 189-203 (1974).

31. Rochereau, N. et al. Dectin-1 is essential for reverse transcytosis of glycosylated SlgA-antigen complexes by intestinal M cells. PLoS Biol. 11, e1001658 (2013).

32. Rol, N., Favre, L., Benyacoub, J. \& Corthésy, B. The role of secretory immunoglobulin $A$ in the natural sensing of commensal bacteria by mouse Peyer's patch dendritic cells. J. Biol. Chem. 287, 40074-40082 (2012).

33. Mabbott, N. A., Donaldson, D. S., Ohno, H., Williams, I. R. \& Mahajan, A. Microfold (M) cells: important immunosurveillance posts in the intestinal epithelium. Mucosal Immunol. 6, 666-677 (2013).

34. Neutra, M. R., Pringault, E. \& Kraehenbuhl, J. P. Antigen sampling across epithelial barriers and induction of mucosal immune responses. Annu. Rev. Immunol. 14, 275-300 (1996).

35. Neutra, M. R., Mantis, N. J. \& Kraehenbuhl, J. P. Collaboration of epithelial cells with organized mucosal lymphoid tissues. Nat. Immunol. 2, 1004-1009 (2001).

36. Rios, D. et al. Antigen sampling by intestinal $M$ cells is the principal pathway initiating mucosal $\lg \mathrm{A}$ production to commensal enteric bacteria. Mucosal Immunol. 9, 907-916 (2016).
37. Gullberg, E. et al. Expression of specific markers and particle transport in a new human intestinal M-cell model. Biochem. Biophys. Res. Commun. 279, 808-813 (2000).

38. Bjerke, K., Brandtzaeg, P. \& Fausa, O. T cell distribution is different in follicleassociated epithelium of human Peyer's patches and villous epithelium. Clin. Exp. Immunol. 74, 270-275 (1988).

39. Brandtzaeg, P. \& Bjerke, K. Immunomorphological characteristics of human Peyer's patches. Digestion 46, 262-273 (1990).

40. Farstad, I. N., Halstensen, T. S., Fausa, O. \& Brandtzaeg, P. Heterogeneity of Mcell-associated B and T cells in human Peyer's patches. Immunology 83, 457-464 (1994).

41. Barone, F., Patel, P., Sanderson, J. D. \& Spencer, J. Gut-associated lymphoid tissue contains the molecular machinery to support T-cell-dependent and T-cellindependent class switch recombination. Mucosal Immunol. 2, 495-503 (2009).

42. Poulin, L. F. et al. DNGR-1 is a specific and universal marker of mouse and human Batf3-dependent dendritic cells in lymphoid and nonlymphoid tissues. Blood 119, 6052-6062 (2012).

43. Wagner, C. et al. Differentiation paths of Peyer's patch LysoDCs are linked to sampling site positioning, migration, and T cell priming. Cell Rep. 31, 107479 (2020).

44. Spencer, J., Finn, T. \& Isaacson, P. G. Human Peyer's patches: an immunohistochemical study. Gut 27, 405-410 (1986).

45. Lelouard, H., Fallet, M., de Bovis, B., Méresse, S. \& Gorvel, J. P. Peyer's patch dendritic cells sample antigens by extending dendrites through $\mathrm{M}$ cell-specific transcellular pores. Gastroenterology 142, 592-601.e3 (2012).

46. Bjerke, K. \& Brandtzaeg, P. Immunoglobulin- and J chain-producing cells associated with lymphoid follicles in the human appendix, colon and ileum, including Peyer's patches. Clin. Exp. Immunol. 64, 432-441 (1986).

47. Falini, B. et al. Expression of the IRTA1 receptor identifies intraepithelial and subepithelial marginal zone B cells of the mucosa-associated lymphoid tissue (MALT). Blood 102, 3684-3692 (2003).

48. Ehrhardt, G. R. et al. Expression of the immunoregulatory molecule FcRH4 defines a distinctive tissue-based population of memory B cells. J. Exp. Med. 202, 783-791 (2005).

49. Sohn, H. W., Krueger, P. D., Davis, R. S. \& Pierce, S. K. FcRL4 acts as an adaptive to innate molecular switch dampening BCR signaling and enhancing TLR signaling. Blood 118, 6332-6341 (2011).

50. Kelsall, B. L. \& Strober, W. Distinct populations of dendritic cells are present in the subepithelial dome and T cell regions of the murine Peyer's patch. J. Exp. Med. 183, 237-247 (1996).

51. Bonnardel, J. et al. Innate and adaptive immune functions of peyer's patch monocyte-derived cells. Cell Rep. 11, 770-784 (2015).

52. Reboldi, A. et al. IgA production requires B cell interaction with subepithelial dendritic cells in Peyer's patches. Science 352, aaf4822 (2016).

53. Komban, R. J. et al. Activated Peyer's patch $B$ cells sample antigen directly from M cells in the subepithelial dome. Nat. Commun. 10, 2423 (2019).

54. Brandtzaeg, P. Function of mucosa-associated lymphoid tissue in antibody formation. Immunol. Invest. 39, 303-355 (2010).

55. Yamanaka, T. et al. Cell pockets of human Peyer's patches are specialized extensions of germinal centers. Eur. J. Immunol. 31, 107-117 (2001).

56. Spencer, J., Siu, J. H. Y. \& Montorsi, L. Human intestinal lymphoid tissue in time and space. Mucosal Immunol. 12, 296-298 (2019).

57. Spencer, J., Barone, F. \& Dunn-Walters, D. Generation of Immunoglobulin diversity in human gut-associated lymphoid tissue. Semin Immunol. 21, 139-146 (2009).

58. Spencer, J. \& Sollid, L. M. The human intestinal B-cell response. Mucosal Immunol. 9, 1113-1124 (2016).

59. Zhao, Y. et al. Spatiotemporal segregation of human marginal zone and memory B cell populations in lymphoid tissue. Nat. Commun. 9, 3857 (2018).

60. Weller, S. et al. Human blood IgM "memory" B cells are circulating splenic marginal zone $B$ cells harboring a prediversified immunoglobulin repertoire. Blood 104, 3647-3654 (2004).

61. Cerutti, A., Cols, M. \& Puga, I. Marginal zone B cells: virtues of innate-like antibody-producing lymphocytes. Nat. Rev. Immunol. 13, 118-132 (2013).

62. Fenton, T. M. et al. Immune profiling of human gut-associated lymphoid tissue identifies a role for isolated lymphoid follicles in priming of region-specific immunity. Immunity 52, 557-570.e6 (2020).

63. Farstad, I. N., Halstensen, T. S., Kvale, D., Fausa, O. \& Brandtzaeg, P. Topographic distribution of homing receptors on $B$ and $T$ cells in human gut-associated lymphoid tissue: relation of L-selectin and integrin alpha 4 beta 7 to naive and memory phenotypes. Am. J. Pathol. 150, 187-199 (1997).

64. Vossenkämper, A. et al. A role for gut-associated lymphoid tissue in shaping the human B cell repertoire. J. Exp. Med. 210, 1665-1674 (2013).

65. Brandtzaeg, P. et al. The B-cell system of human mucosae and exocrine glands. Immunol. Rev. 171, 45-87 (1999). 
66. Erle, D. J. et al. Expression and function of the MAdCAM-1 receptor, integrin alpha 4 beta 7, on human leukocytes. J. Immunol. 153, 517-528 (1994). PMID: 7517418.

67. Grant, A. J., Lalor, P. F., Hübscher, S. G., Briskin, M. \& Adams, D. H. MAdCAM-1 expressed in chronic inflammatory liver disease supports mucosal lymphocyte adhesion to hepatic endothelium (MAdCAM-1 in chronic inflammatory liver disease). Hepatology 33, 1065-1072 (2001).

68. Uzzan, M. et al. Anti- $\alpha 4 \beta 7$ therapy targets lymphoid aggregates in the gastrointestinal tract of HIV-1-infected individuals. Sci. Transl. Med. 10, eaau4711 (2018).

69. Farstad, I. N., Norstein, J. \& Brandtzaeg, P. Phenotypes of B and T cells in human intestinal and mesenteric lymph. Gastroenterology 112, 163-173 (1997).

70. Bergqvist, P., Gärdby, E., Stensson, A., Bemark, M. \& Lycke, N. Y. Gut IgA class switch recombination in the absence of CD40 does not occur in the lamina propria and is independent of germinal centers. J. Immunol. 177, 7772-7783 (2006).

71. Bergqvist, P., Stensson, A., Lycke, N. Y. \& Bemark, M. T cell-independent IgA class switch recombination is restricted to the GALT and occurs prior to manifest germinal center formation. J. Immunol. 184, 3545-3553 (2010).

72. Tsuji, M. et al. Requirement for lymphoid tissue-inducer cells in isolated follicle formation and $\mathrm{T}$ cell-independent immunoglobulin $\mathrm{A}$ generation in the gut. Immunity 29, 261-271 (2008).

73. Lindner, C. et al. Diversification of memory B cells drives the continuous adaptation of secretory antibodies to gut microbiota. Nat. Immunol. 16, 880-888 (2015).

74. Barone, F. et al. IgA-producing plasma cells originate from germinal centers that are induced by B-cell receptor engagement in humans. Gastroenterology 140, 947-956 (2011).

75. Gibbons, D. L. \& Spencer, J. Mouse and human intestinal immunity: same ballpark, different players; different rules, same score. Mucosal Immunol. 4, 148-157 (2011).

76. Reboldi, A. \& Cyster, J. G. Peyer's patches: organizing B-cell responses at the intestinal frontier. Immunol. Rev. 271, 230-245 (2016).

77. Pabst, O. et al. Chemokine receptor CCR9 contributes to the localization of plasma cells to the small intestine. J. Exp. Med. 199, 411-416 (2004).

78. Mora, J. R. et al. Selective imprinting of gut-homing $T$ cells by Peyer's patch dendritic cells. Nature 424, 88-93 (2003).

79. Mora, J. R. et al. Generation of gut-homing lgA-secreting B cells by intestinal dendritic cells. Science 314, 1157-1160 (2006).

80. Kunkel, E. J. et al. Lymphocyte CC chemokine receptor 9 and epithelial thymusexpressed chemokine (TECK) expression distinguish the small intestinal immune compartment: Epithelial expression of tissue-specific chemokines as an organizing principle in regional immunity. J. Exp. Med. 192, 761-768 (2000).

81. Zabel, B. A. et al. Human G protein-coupled receptor GPR-9-6/CC chemokine receptor 9 is selectively expressed on intestinal homing $T$ lymphocytes, mucosal lymphocytes, and thymocytes and is required for thymus-expressed chemokinemediated chemotaxis. J. Exp. Med. 190, 1241-1256 (1999).

82. Svensson, M. et al. CCL25 mediates the localization of recently activated CD8alphabeta $(+)$ lymphocytes to the small-intestinal mucosa. J. Clin. Invest. 110, 1113-1121 (2002).

83. Rasmussen, T., Fonnes, S. \& Rosenberg, J. Long-term complications of appendectomy: a systematic review. Scand. J. Surg. 107, 189-196 (2018).

84. Randal Bollinger, R., Barbas, A. S., Bush, E. L., Lin, S. S. \& Parker, W. Biofilms in the large bowel suggest an apparent function of the human vermiform appendix. J. Theor. Biol. 249, 826-831 (2007).

85. Spencer, J., Finn, T. \& Isaacson, P. G. Gut associated lymphoid tissue: a morphological and immunocytochemical study of the human appendix. Gut 26, 672-679 (1985).

86. Magri, G. et al. Human secretory IgM emerges from plasma cells clonally related to gut memory B cells and targets highly diverse commensals. Immunity 47, 118-134.e8 (2017)

87. Cosnes, J. et al. Effects of appendicectomy on the course of ulcerative colitis. Gut 51, 803-807 (2002).

88. Myrelid, P., Landerholm, K., Nordenvall, C., Pinkney, T. D. \& Andersson, R. E. Appendectomy and the risk of colectomy in ulcerative colitis: A National Cohort Study. Am. J. Gastroenterol. 112, 1311-1319 (2017).

89. Sahami, S. et al. Appendectomy for therapy-refractory ulcerative colitis results in pathological improvement of colonic inflammation: short-term results of the PASSION study. J. Crohns Colitis 13, 165-171 (2019).

90. Park, S. H. et al. Long term follow-up of appendiceal and distal right-sided colonic inflammation. Endoscopy 44, 95-98 (2012).

91. Bockman, D. E. \& Cooper, M. D. Early lymphoepithelial relationships in human appendix. A combined light- and electron-microscopic study. Gastroenterology 68, 1160-1168 (1975).

92. Hansen, K. et al. Reference values for second trimester fetal and neonatal organ weights and measurements. Pediatr. Dev. Pathol. 6, 160-167 (2003).
93. Schumpelick, V., Dreuw, B., Ophoff, K. \& Prescher, A. Appendix and cecum. Embryology, anatomy, and surgical applications. Surg. Clin. North Am. 80, 295-318 (2000).

94. Takeuchi, T. Factors involved in the degeneration of lymphoid tissue in the appendix. Kurum. Med. J. 65, 123-127 (2020).

95. Verbrugghe, P., Kujala, P., Waelput, W., Peters, P. J. \& Cuvelier, C. A. Clusterin in human gut-associated lymphoid tissue, tonsils, and adenoids: localization to $M$ cells and follicular dendritic cells. Histochem Cell Biol. 129, 311-320 (2008).

96. Granot, T. et al. Dendritic cells display subset and tissue-specific maturation dynamics over human life. Immunity 46, 504-515 (2017).

97. Steiniger, B., Timphus, E. M., Jacob, R. \& Barth, P. J. CD27+ B cells in human lymphatic organs: re-evaluating the splenic marginal zone. Immunology 116, 429-442 (2005)

98. Bjerke, K., Brandtzaeg, P. \& Rognum, T. O. Distribution of immunoglobulin producing cells is different in normal human appendix and colon mucosa. Gut 27, 667-674 (1986).

99. Jørgensen P. B. et al. Identification, isolation and analysis of human gut-associated lymphoid tissues. Nat. Protoc. https://doi.org/10.1038/s41596-020-00482-1 (2021).

100. Langman, J. M. \& Rowland, R. The number and distribution of lymphoid follicles in the human large intestine. J. Anat. 149, 189-194 (1986).

101. Dukes, C. \& Bussey, H. J. R. The number of lymphoid follicles of the human large intestine. J. Pathol. Bacteriol. 29, 111-116 (1926).

102. Hellmann, T. Studien über das lymphoide Gewebe. IV. Zur Frage des Status lymphaticus. Untersuchungen über die Menge des lymphoiden Gewebes, besonders des Darmes beim Menschen mittels einer quantitativen Bestimmungsmethode. Zeitschr. f. d. ges. Anat., Il. kbt.: Zeitschr. f. Konstitutionsl. Bd. 8, H. 3, S. 191-219 (1921).

103. Trepel, F. Number and distribution of lymphocytes in man. A critical analysis. Klin. Wochenschr. 52, 511-515 (1974).

104. Pabst, O. et al. Cryptopatches and isolated lymphoid follicles: dynamic lymphoid tissues dispensable for the generation of intraepithelial lymphocytes. Eur. J. Immunol. 35, 98-107 (2005).

105. Rosner, A. J. \& Keren, D. F. Demonstration of M cells in the specialized follicleassociated epithelium overlying isolated lymphoid follicles in the gut. J. Leukoc. Biol. 35, 397-404 (1984).

106. Liebler-Tenorio, E. M. \& Pabst, R. MALT structure and function in farm animals. Vet. Res. 37, 257-280 (2006)

107. Hitotsumatsu, O. et al. Identification and characterization of novel gut-associated lymphoid tissues in rat small intestine. J. Gastroenterol. 40, 956-963 (2005).

108. Hamada, $\mathrm{H}$. et al. Identification of multiple isolated lymphoid follicles on the antimesenteric wall of the mouse small intestine. J. Immunol. 168, 57-64 (2002).

109. Kanamori, Y. et al. Identification of novel lymphoid tissues in murine intestinal mucosa where clusters of c-kit+ IL-7R+ Thy1+ lympho-hemopoietic progenitors develop. J. Exp. Med. 184, 1449-1459 (1996).

110. McDonald, K. G., McDonough, J. S., Dieckgraefe, B. K. \& Newberry, R. D. Dendritic cells produce $\mathrm{CXCL13}$ and participate in the development of murine small intestine lymphoid tissues. Am. J. Pathol. 176, 2367-2377 (2010).

111. Kiss, E. A. et al. Natural aryl hydrocarbon receptor ligands control organogenesis of intestinal lymphoid follicles. Science 334, 1561-1565 (2011).

112. Bouskra, D. et al. Lymphoid tissue genesis induced by commensals through NOD1 regulates intestinal homeostasis. Nature 456, 507-510 (2008).

113. Donaldson, D. S., Bradford, B. M., Artis, D. \& Mabbott, N. A. Reciprocal regulation of lymphoid tissue development in the large intestine by IL-25 and IL-23. Mucosal Immunol. 8, 582-595 (2015).

114. Pabst, O. et al. Adaptation of solitary intestinal lymphoid tissue in response to microbiota and chemokine receptor CCR7 signaling. J. Immunol. 177, 6824-6832 (2006).

115. McDonald, K. G., Leach, M. R., Huang, C., Wang, C. \& Newberry, R. D. Aging impacts isolated lymphoid follicle development and function. Immun. Ageing $\mathbf{8}$, 1 (2011).

116. Eberl, G. \& Sawa, S. Opening the crypt: current facts and hypotheses on the function of cryptopatches. Trends Immunol. 31, 50-55 (2010).

117. Moghaddami, M., Cummins, A. \& Mayrhofer, G. Lymphocyte-filled villi: comparison with other lymphoid aggregations in the mucosa of the human small intestine. Gastroenterology 115, 1414-1425 (1998).

118. Lügering, A. et al. CCR6 identifies lymphoid tissue inducer cells within cryptopatches. Clin. Exp. Immunol. 160, 440-449 (2010).

119. Pearson, C. et al. ILC3 GM-CSF production and mobilisation orchestrate acute intestinal inflammation. Elife 5, e10066 (2016).

120. Emgård, J. et al. Oxysterol sensing through the receptor GPR183 promotes the lymphoid-tissue-inducing function of innate lymphoid cells and colonic inflammation. Immunity 48, 120-132.e8 (2018).

121. Gustafson, C. E. et al. Limited expression of APRIL and its receptors prior to intestinal IgA plasma cell development during human infancy. Mucosal Immunol. 7, 467-477 (2014). 
122. Spencer, J., Klavinskis, L. S. \& Fraser, L. D. The human intestinal IgA response; burning questions. Front Immunol. 3, 108 (2012)

123. Russell, G. J., Bhan, A. K. \& Winter, H. S. The distribution of T and B lymphocyte populations and MHC class II expression in human fetal and postnatal intestine. Pediatr. Res. 27, 239-244 (1990).

124. Fawkner-Corbett, D. et al. Spatiotemporal analysis of human intestinal development at single-cell resolution. Cell 184, 810-826.e23 (2021).

125. Knoop, K. A., Butler, B. R., Kumar, N., Newberry, R. D. \& Williams, I. R. Distinct developmental requirements for isolated lymphoid follicle formation in the small and large intestine: RANKL is essential only in the small intestine. Am. J. Pathol. 179, 1861-1871 (2011).

126. Cummings, J. H., Pomare, E. W., Branch, W. J., Naylor, C. P. \& Macfarlane, G. T. Short chain fatty acids in human large intestine, portal, hepatic and venous blood. Gut 28, 1221-1227 (1987).

127. Villablanca, E. J. et al. MyD88 and retinoic acid signaling pathways interact to modulate gastrointestinal activities of dendritic cells. Gastroenterology 141, 176-185 (2011)

128. James, K. R. et al. Distinct microbial and immune niches of the human colon. Nat. Immunol. 21, 343-353 (2020).

129. Koh, A., De Vadder, F., Kovatcheva-Datchary, P. \& Bäckhed, F. From dietary fiber to host physiology: short-chain fatty acids as key bacterial metabolites. Cell 165, 1332-1345 (2016).

130. O'Leary, A. D. \& Sweeney, E. C. Lymphoglandular complexes of the colon: structure and distribution. Histopathology 10, 267-283 (1986).

131. Jacob, E., Baker, S. J. \& Swaminathan, S. P. 'M' cells in the follicle-associated epithelium of the human colon. Histopathology 11, 941-952 (1987).

132. O'Leary, A. D. \& Sweeney, E. C. Lymphoglandular complexes of the normal colon: histochemistry and immunohistochemistry. Ir. J. Med. Sci. 156, 142-148 (1987).

133. O'Leary, A. D. \& Sweeney, E. C. Lymphoglandular complexes in the diseased colon. Ir. J. Med Sci. 156, 353-360 (1987).

134. Junker, Y. et al. Comparative analysis of mononuclear cells isolated from mucosal lymphoid follicles of the human ileum and colon. Clin. Exp. Immunol. 156, 232-237 (2009).

135. Hase, K. et al. Uptake through glycoprotein 2 of $\mathrm{FimH}(+)$ bacteria by $\mathrm{M}$ cells initiates mucosal immune response. Nature 462, 226-230 (2009).

136. Dunn-Walters, D. K., Boursier, L. \& Spencer, J. Hypermutation, diversity and dissemination of human intestinal lamina propria plasma cells. Eur. J. Immunol. 27, 2959-2964 (1997).

137. Meier, D. et al. Immunological status of isolated lymphoid follicles after intestinal transplantation. Am. J. Transpl. 14, 2148-2158 (2014).

138. Boursier, L., Gordon, J. N., Thiagamoorthy, S., Edgeworth, J. D. \& Spencer, J. Human intestinal $\lg \mathrm{A}$ response is generated in the organized gut-associated lymphoid tissue but not in the lamina propria. Gastroenterology 128, 1879-1889 (2005).

139. Kim, S. V. et al. GPR15-mediated homing controls immune homeostasis in the large intestine mucosa. Science 340, 1456-1459 (2013).

140. Nguyen, L. P. et al. Role and species-specific expression of colon T cell homing receptor GPR15 in colitis. Nat. Immunol. 16, 207-213 (2015).

141. Martinoli, C., Chiavelli, A. \& Rescigno, M. Entry route of Salmonella typhimurium directs the type of induced immune response. Immunity 27, 975-984 (2007).

142. Hashizume, T. et al. Peyer's patches are required for intestinal immunoglobulin A responses to Salmonella spp. Infect. Immun. 76, 927-934 (2008).

143. Nagai, S. et al. Role of Peyer's patches in the induction of Helicobacter pyloriinduced gastritis. Proc. Natl Acad. Sci. USA 104, 8971-8976 (2007)

144. Griffin, A. J. \& McSorley, S. J. Development of protective immunity to Salmonella, a mucosal pathogen with a systemic agenda. Mucosal Immunol. 4, 371-382 (2011).

145. Kim, S. H. \& Jang, Y. S. Yersinia enterocolitica exploits signal crosstalk between complement 5 a receptor and toll-like receptor $1 / 2$ and 4 to avoid the bacterial clearance in M cells. Immune Netw. 17, 228-236 (2017).

146. Autenrieth, I. B. \& Firsching, R. Penetration of $M$ cells and destruction of Peyer's patches by Yersinia enterocolitica: an ultrastructural and histological study. J. Med. Microbiol. 44, 285-294 (1996).

147. Rey, C. et al. Transcytosis subversion by M cell-to-enterocyte spread promotes Shigella flexneri and Listeria monocytogenes intracellular bacterial dissemination. PLoS Pathog. 16, e1008446 (2020).

148. Siciński, P. et al. Poliovirus type 1 enters the human host through intestinal M cells. Gastroenterology 98, 56-58 (1990).

149. Nair, V. R. et al. Microfold cells actively translocate mycobacterium tuberculosis to initiate infection. Cell Rep. 16, 1253-1258 (2016).

150. Donaldson, D. S. et al. M cell-depletion blocks oral prion disease pathogenesis. Mucosal Immunol. 5, 216-225 (2012).
151. Hird, T. R. \& Grassly, N. C. Systematic review of mucosal immunity induced by oral and inactivated poliovirus vaccines against virus shedding following oral poliovirus challenge. PLoS Pathog. 8, e1002599 (2012).

152. Bishop, A. L. \& Camilli, A. Vibrio cholerae: lessons for mucosal vaccine design. Expert Rev. Vaccines 10, 79-94 (2011).

153. D'Amelio, R. et al. Comparative analysis of immunological responses to oral (Ty21a) and parenteral (TAB) typhoid vaccines. Infect. Immun. 56, 2731-2735 (1988).

154. Kozlowski, P. A., Cu-Uvin, S., Neutra, M. R. \& Flanigan, T. P. Comparison of the oral, rectal, and vaginal immunization routes for induction of antibodies in rectal and genital tract secretions of women. Infect. Immun. 65, 1387-1394 (1997).

155. Blisnick, T., Ave, P., Huerre, M., Carniel, E. \& Demeure, C. E. Oral vaccination against bubonic plague using a live avirulent Yersinia pseudotuberculosis strain. Infect. Immun. 76, 3808-3816 (2008).

156. Corridoni, D. et al. Single-cell atlas of colonic CD8+ T cells in ulcerative colitis. Nat. Med. 26, 1480-1490 (2020).

157. Castro-Dopico, T. et al. Anti-commensal lgG drives intestinal inflammation and type 17 immunity in ulcerative colitis. Immunity 50, 1099-1114.e10 (2019).

158. Martin, J. C. et al. Single-Cell Analysis of Crohn's Disease Lesions Identifies a Pathogenic Cellular Module Associated with Resistance to Anti-TNF Therapy. Cell 178, 1493-1508.e20 (2019).

159. Smillie, C. S. et al. Intra- and inter-cellular rewiring of the human colon during ulcerative colitis. Cell 178, 714-730.e22 (2019).

160. Neurath, M. F. Targeting immune cell circuits and trafficking in inflammatory bowel disease. Nat. Immunol. 20, 970-979 (2019).

161. Fujimura, Y., Kamoi, R. \& lida, M. Pathogenesis of aphthoid ulcers in crohn's disease: correlative findings by magnifying colonoscopy, electron microscopy, and immunohistochemistry. Gut 38, 724-732 (1996).

162. Gullberg, E. \& Söderholm, J. D. Peyer's Patches and M Cells as potential sites of the inflammatory onset in Crohn's disease. Ann. N. Y Acad. Sci. 1072, 218-232 (2006).

163. Krauss, E. et al. Characterization of lymphoid follicles with red ring signs as first manifestation of early Crohn's disease by conventional histopathology and confocal laser endomicroscopy. Int. J. Clin. Exp. Pathol. 5, 411-421 (2012)

164. Hokama, A. et al. Crohn's disease: aphthoid to longitudinal ulcers. Gastrointest. Endosc. 57, 388-389 (2003).

165. Smids, $C$. et al. Cell profiling in inflammatory bowel disease: linking $T$ cell subsets to disease activity and disease course. J. Crohns Colitis 12, 465-475 (2018).

166. Horjus Talabur Horje, C. S. et al. High endothelial venules associated with T cell subsets in the inflamed gut of newly diagnosed inflammatory bowel disease patients. Clin. Exp. Immunol. 188, 163-173 (2017).

167. Rochereau, N. et al. NOD2 deficiency increases retrograde transport of secretory IgA complexes in Crohn's disease. Nat. Commun. 12, 261 (2021).

168. Neurath, M. F. Current and emerging therapeutic targets for IBD. Nat. Rev. Gastroenterol. Hepatol. 14, 269-278 (2017)

169. Yeung, M. et al. Characterisation of mucosal lymphoid aggregates in ulcerative colitis: immune cell phenotype and TcR- $\gamma \delta$ expression. Gut 47, 215-227 (2000).

170. Sitohy, B., Hammarström, S., Danielsson, A. \& Hammarström, M. L. Basal lymphoid aggregates in ulcerative colitis colon: a site for regulatory $\mathrm{T}$ cell action. Clin. Exp. Immunol. 151, 326-333 (2008).

171. Surawicz, C. M., Haggitt, R. C., Husseman, M. \& McFarland, L. V. Mucosal biopsy diagnosis of colitis: acute self-limited colitis and idiopathic inflammatory bowel disease. Gastroenterology 107, 755-763 (1994).

172. Surawicz, C. M. \& Belic, L. Rectal biopsy helps to distinguish acute self-limited colitis from idiopathic inflammatory bowel disease. Gastroenterology 86, 104-113 (1984).

173. Odze, R., Antonioli, D., Peppercorn, M. \& Goldman, H. Effect of topical 5aminosalicylic acid (5-ASA) therapy on rectal mucosal biopsy morphology in chronic ulcerative colitis. Am. J. Surg. Pathol. 17, 869-875 (1993).

174. Kinchen, J. et al. Structural remodeling of the human colonic mesenchyme in inflammatory bowel disease. Cell 175, 372-386.e17 (2018).

175. Yeong, M. L., Bethwaite, P. B., Prasad, J. \& Isbister, W. H. Lymphoid follicular hyperplasia-a distinctive feature of diversion colitis. Histopathology 19, 55-61 (1991).

176. Brandtzaeg, P., Carlsen, H. S. \& Halstensen, T. S. The B-cell system in inflammatory bowel disease. Adv. Exp. Med Biol. 579, 149-167 (2006).

177. McNamee, E. N. \& Rivera-Nieves, J. Ectopic tertiary lymphoid tissue in inflammatory bowel disease: protective or provocateur? Front Immunol. 7, 308 (2016).

178. Maoz, A., Dennis, M. \& Greenson, J. K. The Crohn's-like lymphoid reaction to colorectal cancer-tertiary lymphoid structures with immunologic and potentially therapeutic relevance in colorectal cancer. Front Immunol. 10, 1884 (2019). 